\title{
LIII. Change of period of electrical waves on iron wires
}

\section{John Trowbridge}

To cite this article: John Trowbridge (1894) LIII. Change of period of electrical waves on iron wires, Philosophical Magazine Series 5, 38:234, 441-445, DOI: $10.1080 / 14786449408620659$

To link to this article: http://dx.doi.org/10.1080/14786449408620659

曲 Published online: 08 May 2009.

Submit your article to this journal $\pi$

Џll Article views: 2

Q View related articles $\sqsubset$ 
Periodicity of Electrical Wares on Iron Wires.

I wish to express my great obligation to Prof. John Trowbridge for the encouragement and suggestions that $I$ have received from him.

\section{Conclusions.}

1. The self-induction of iron circuits is greater than that of similar copper circuits under very rapid electric oscillations ( $115 \times 10^{6}$ reversals per second). The change in self-induction varies from $3 \cdot 4$ to $4 \cdot 3$ per cent. in the present investigation and increases with decreasing diameters.

2. The increase in self-induction produces greater damping, and a shortening of the wave-length of 1.5 to 2 per cent.

3 . The permeability $\mu$ of annealed iron wire under this rate of alternation is about 385 .

4. For oscillations of the same period, the wave-length along parallel copper wires varies directly with the diameter of the wires. (Range of wires used 0.03915 centim. to 0.1201 centim.) The maximum decrease observed is 5 per cent.

Jefferson Physical Laboratory, July 24,1894 .

LIII. Change of Period of Electrical Waves on Iron Wires. By JoHN Trowbridge*

$\mathrm{T}$ an investigation upon the damping of electrical waves 1 on iron wires $\dagger$, I endeavoured to detect a change of periodicity as well as a damping of these waves. On account, however, of the strong damping effect exerterl by the magnetic nature of the conductors, not a sufficient number of oscillations could be set up in them to enable one to make conclusive measurements. With more powerful means of experimenting I returned to the subject, and I have detected a marked change in the period of electrical waves which is produced by the magnetic nature of the wire. At the same time Mr. Charles E. St. John, working in the Jefferson Physical Laboratory, by an entirely different method, has shown a change in wavelength on iron wire even for the very rapid period of the Hertz vibrator. It will be remembered that Hertz believed that iron wires behaved like copper wires when transmitting very rapid electrical oscillations. Stefan $\ddagger$ in a recent paper gives an analysis of electrical oscillations, in which he proves that rapid electrical waves on iron-wire circuits have the same wave-length as those on copper circuits of the same geome-

* Communicated by the Author.

+ Phil. Mag. Dec. 1891 .

$\ddagger$ Wied. Ann. xli. 1890, p. 422.

Phil. Mag. S. 5. Vol. 38. No. 234. Nov. 1894. $2 \mathrm{H}$ 
trical form-the electrostatic capacity of the two circuits being the same.

With reference, therefore, both to the theory of electrical waves and to the theories of magnetism, it seems important to determine whether there is a lengthening of electrical waves on iron wires.

The method of investigation I employed was the same as that which $I$ have described in my paper on the damping of electrical waves on iron wires. A leyden jar was discharged through the given wires and the resulting spark, spread out by a revolving mirror, was photographed. The apparatus was also modified as I have described in my paper on "Electrical Resonance and Electrical Interference" *.

It was important in this investigation to be able to compare the times of oscillation on the iron circuits and the copper circuits, and it seemed best to employ some method of imprinting, so to speak, the time of a standard circuit on each photograph, beside the photograph of the spark produced on either the iron circuit or the copper circuit; for if the speed of the mirror changed, this change could be readily detected by the measurements of the oscillations of the standard time-spark. At the first thought it seemed a comparatively simple matter to arrange a suitable time circuit. In Hertz, 'Electric Waves' + , appendix p. 271 , it is stated :-

" Let the primary coils of two induction-coils be placed in the same circuit, and let their spark-gaps be so adjusted as to be just on the point of sparking. Any cause which starts sparking in one of them will now make the other begin to spark as well; and this quite independently of the mutual action of the light emitted by the two sparks, which, indeed, can easily be excluded."

I therefore slipped two induction-coils of exactly the same self-induction on a long electromagnet, placing them symmetrically upon it. In the circuits of these induction-coils I placed the same amount of capacity. The spark-gap on the time circuit was made of the same length as that on a circuit of iron or copper wire which was under examination. I expected thus to obtain a photograph of the spark on my standard circuit at the same instant as that of the spark on the trial circuit of iron or copper. To my surprise, I found that the two induction-coils did not respond at the same instant to the impulse in the electromagnet, when the spark-gaps were of the same length. It was necessary to make careful adjustment of these lengths and to modify the amount of * Phil. Mag. Aug. 1894.

† 'Electric Waves,' Dr. Heinrich Hertz, translated by D. E. Jones, B.Sc. 
capacity of the circuits. This want of isochronism may have been due to irregularities in the hard rubber condensers which I employed. This, however, does not seem probable. The condensers were made of sheets of hard rubber one eighth of an inch in thickness, covered with tinfoil, and the set of condensers in the time circuit did not differ geometrically appreciably from the set in the trial circuit. The electrical disturbance on such a connected system is evidently a complicated one when its various reactions are considered, and the statement given by Hertz, which I have quoted, must be modified if there is any capacity in the circuits of the two Ruhmkorf coils which have a common primary.

The capacity in the time circuit was the same geometrically as that in the circuit which included the wires under examination. A suitable amount of self-induction was placed in the time circuit. To ascertain whether the time circuit could be relied upon, I made many measurements of the ratio of the oscillations in the time circuit to those in the trial circuit, which contained copper wires and the same geomstrical capacity. I had no reason to suspect a change in the selfinduction in my time cirenit; a change might occur, however, in the capacity of the indiarubber condensers, due possibly to hysteresis from electric strains and deformations. I could not detect, however, such effects. I was dealing with single discharges, not repeated ones, such as are employed in obtaining wave-lengths along wires, and the photographs of such single discharges showed no evidence of inconstancy in the capacity of my condensers. If there was any effect of electrical hysteresis, it affected my time circuit and my trial circuit alike.

As an example of the degree of accuracy which can be obtained in the measurement of the distances between the oscillations on the negative, the following table is given. The distances between different numbers of oscillations is given in the first column and the average length of the oscillations is given in the third column.

\begin{tabular}{|c|c|c|}
\hline $\begin{array}{c}\text { Distance in millim. } \\
\text { between the first and } \\
\text { last oscillations. }\end{array}$ & $\begin{array}{c}\text { Number of oscillations } \\
\text { included in this } \\
\text { distance. }\end{array}$ & $\begin{array}{c}\text { Average length of } \\
\text { oscillations in millim. }\end{array}$ \\
\hline 22.5 & 6 & 375 \\
26.1 & 7 & 373 \\
30.0 & 8 & 377 \\
$15 \cdot 1$ & 4 & 377 \\
\hline
\end{tabular}

$2 \mathrm{H} 2$ 


\section{Prof. John Trowbridge on the Change of Period}

Repeated measures between the same number of oscillations give eloser results; but one is apt to set the measuring instrument each time on the same points on the negative. It is evident that measuring each time the space between a different number of oscillations gives the fairest result. It is surprising how close one can set the measuring instrument upon the serrations of the negative.

It will be noticed that the ratio between any two determinations of the time on the time circuit is the same as that between the corresponding times on the trial circuits. When iron wire of suitable diameter, however, was substituted for copper wire of the same diameter and same geometrical form in the trial circuits, the ratio of the determinations of time in the time circuit and the ratio of the oscillations in the iron circuit were no longer constant. This inconstancy I desire to dwell upon as my strongest proof that the period of electrical oscillations on iron wires is not the same as that of oscillations on copper wires of the same geometrical form.

The arrangement of a suitable iron circuit gave me considerable trouble. The problem was to obtain a sufficient length of iron wire to show any effect of change in periodicity, and also to obtain a sufficient amount of self-induction, in order that the distances between the oscillations on the photograph should be measurable. The strong damping effect of iron did not permit of my using more than four or five metres of wire. It was not a simple matter to arrange two circuits, one of iron and one of copper, which would have exactly the same geometrical form. After many trials I arranged my trial circuit as follows:-

A cylinder of very porous wood, 11.5 centim. in diameter, 15 centim. long, was boiled in paraffin, and a spiral was cut upon its surface. The turns of the spiral were 1 centim. apart. On this cylinder and in these spirals the wires under examination were wound. After a determination had been made with a copper wire it was unwound from the cylinder and an iron or steel wire was wound in the grooves occupied by the copper wire. Exact geometrical similarity was thus obtained with good insulation. Several hundred determinations were made with wires of different sizes. With iron wires larger than -0312 inch in diameter, no marked change in period could be perceived. If a great number, however, of photographs were measured, an inconstancy of ratios was noticed which never appeared when the copper circuits were compared. It seemed as if at certain times the iron exerted a magnetic effect and at other times failed to do this. The most marked changes in period I obtained with iron wires of 0312 inch in diameter. 
I give the following example. The lengths of the oscillations are expressed in millimetres.

\begin{tabular}{|c|c|c|c|}
\hline \multicolumn{2}{|c|}{ Iros. } & \multicolumn{2}{|c|}{ CoPPER. } \\
\hline A. & B. & c. & D. \\
\hline $\begin{array}{l}\text { Length of } \\
\text { ossillations on } \\
\text { iron circuit. }\end{array}$ & $\begin{array}{l}\text { Length of } \\
\text { oscillations on } \\
\text { time circuit. }\end{array}$ & $\begin{array}{l}\text { Length of } \\
\text { oscillations on } \\
\text { copper circuit. }\end{array}$ & $\begin{array}{l}\text { Length of } \\
\text { oscillations on } \\
\text { time circuit. }\end{array}$ \\
\hline $3 \cdot 7$ & 6.08 & $3 \cdot 50$ & $6 \cdot 14$ \\
\hline $3 \cdot 7$ & 608 & $3 \cdot 40$ & $6 \cdot 00$ \\
\hline $3 \cdot 7$ & $5^{\circ} 90$ & $3 \cdot 30$ & 6.00 \\
\hline 4.0 & $6 \cdot 10$ & $2 \cdot 70$ & $5 \cdot 26$ \\
\hline $3 \cdot 3$ & $5 \cdot 16$ & 3.40 & $6 \cdot 10$ \\
\hline \multirow[t]{2}{*}{$2 \cdot 8$} & $3 \cdot 60$ & $3 \cdot 37$ & $6 \cdot 36$ \\
\hline & & $2 \cdot 68$ & $3 \cdot 72$ \\
\hline
\end{tabular}

When the ratios of $\mathrm{A}$ to $\mathrm{B}$ and of $\mathrm{C}$ to $\mathrm{D}$ are compared, it will be seen that the time of electrical oscillations on an iron circuit of the same geometrical form as a copper circuit is longer than of those on the copper circuit.

The rate of oscillation was not far from that which I employed in my investigation on the damping effect of iron wires. Since the inductance appears under the square root in the formula $t=\pi \sqrt{\mathrm{LC}}$, the changes in induction due to the iron indicated by the above table may amount to from five to ten per cent.

Thus my results confirm those of Mr. Charles E. St. John, who has shown by an entirely different method that the wavelengths sent out by a Hertzian vibrator on iron wires differ in length from those transmitted on copper wires of the same geometrical form as the iron wires. His results are of even more importance in the theory of magnetism, for they deal with more rapid electrical oscillations than those which I employed.

Jefferson Physical Laboratory. 